\title{
Decolonialidade e estudos críticos do discurso: convergências para abordagens antirracistas no Brasil
}

\author{
Decoloniality and critical discourse studies: \\ convergences for anti-racist approaches in Brazil
}

Caroline Fernanda Santos da Silva*

\begin{abstract}
Resumo - Este trabalho tem como objetivo compreender, analisar e problematizar a forma como os estudos críticos do discurso (ECD) e a perspectiva da decolonialidade podem convergir para uma abordagem antirracista no Brasil. Para isso, o texto está dividido em dois subitens, além da introdução e das considerações finais, que apresentam os conceitos em destaque e problematizam alguns elementos importantes com relação aos mesmos. No primeiro item, apresenta-se uma breve reflexão sobre os fundamentos da produção de conhecimentos, apontando importantes contribuições e questionamentos de autores que abordam a perspectiva decolonial. Na sequência, o texto apresenta uma breve introdução aos estudos críticos do discurso (ECD), situando a relevância de sua utilização para a compreensão, abordagem e análise do racismo no Brasil.
\end{abstract}

Palavras-chave: estudos críticos do discurso; decolonialidade; antirracismo.

\begin{abstract}
This paper aims to understand, analyze, and problematize the way in which critical discourse studies and decoloniality's perspective can converge towards an anti-racist approach to problems in Brazil. The text is divided into two sections, besides the introduction and final considerations, which present the concepts in question and problematize some of their important elements. In the first section, a brief reflection on the fundamentals of the production of knowledge is presented, presenting important contributions and issues raised by authors that approach the decolonial perspective. Following, the text presents a brief introduction to critical discourse studies, highlighting the relevance of its use for the understanding, approach and analysis of racism in Brazil.

Keywords: critical discourse studies; decoloniality; anti-racism.
\end{abstract}

*Assistente Social (ULBRA, 2004). Metre em Serviço Social (PUC Rio, 2009). Doutoranda em Serviço Social - PUCRS. Atua como professora adjunta na Universidade Luterana do Brasil - ULBRA. E-mail: carolfrs@yahoo.com.br. ORCID: https://orcid.org/0000-0002-6348-1345. 


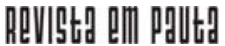

\} DECOLONIALIDADE E ESTUDOS CRÍTICOS - SILVA, C. F. S. \}

DOI: $10.12957 /$ REP.2020.51983

\section{Introdução}

A presente proposta de estudo busca apresentar uma revisão de bibliografia a respeito dos temas em destaque, com o objetivo de compreender, analisar e problematizar a forma como os estudos críticos do discurso (ECD) e a perspectiva da decolonialidade podem convergir para uma abordagem antirracista no Brasil. Tal proposição parte de um compromisso ético-político que busca estratégias para pôr em pauta o racismo no Brasil, rompendo com a lógica do silenciamento que prevalece nas discussões da população em geral e, de forma especial, no ambiente acadêmico - onde a quase ausência desse tema chama atenção para o número reduzido de docentes negros, ao mesmo tempo em que denuncia a pouca habilidade ou pouca aderência dos professores não negros em abordar o tema.

Essa discussão se torna relevante na medida em que tanto a ideia de decolonialidade quanto os estudos críticos do discurso remetem a um tipo de conhecimento que deve ser produzido a partir das culturas subalternas ou dos grupos dominados, conforme será abordado ao longo do texto. Portanto, interessa para estas perspectivas refletir sobre o papel desempenhado pelo conhecimento em sua relação com a sociedade e sobre a forma como esse conhecimento se relaciona com tais grupos subalternos ou dominados - onde se insere a população negra no Brasil.

Diante da constatação de que o racismo faz parte das relações de dominação e exploração na sociedade capitalista, o antirracismo se apresenta como um conjunto de posturas ou comportamentos, éticos e também políticos, a serem desempenhados pelas pessoas na convivência em sociedade. Contudo, a possibilidade do desenvolvimento de posturas antirracistas está diretamente associada à possibilidade primeira de reconhecer a presença do racismo em nossa sociedade.

Este artigo está organizado em dois subitens, além de introdução e considerações finais. Inicia-se o texto com uma breve reflexão sobre os fundamentos da produção de conhecimentos, apresentando importantes contribuições e questionamentos de autores que abordam a perspectiva decolonial. Em seguida, o segundo item fará uma breve introdução aos estudos críticos do discurso, situando a relevância de sua utilização para a compreensão, abordagem e análise do racismo no Brasil.

\section{Breve reflexão sobre a perspectiva decolonial, ou por que mencionar o lugar de fala}

Há muito se discute sobre o papel da ciência em sua relação com o mundo, seja na área das ciências sociais, seja em qualquer outro campo científico. Nesse contexto, alguns questionamentos são constantes, tais como: qual a função do conhecimento científico? Onde se aplica? Qual 


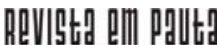

\} DECOLONIALIDADE E ESTUDOS CRÍTICOS - SILVA, C. F. S. \}

DOI: $10.12957 /$ REP.2020.51983

conhecimento pode ser considerado científico? Essas são questões que se relacionam diretamente com o entendimento sobre o papel e a função do pesquisador nos diferentes processos de produção de conhecimento.

Durante longo período, a ciência creditou a função seletiva de definir a validade e a credibilidade do conhecimento à dita "neutralidade científica", amplamente difundida no meio científico em geral. Essa pretensa neutralidade ancorou-se em um tipo de conhecimento que partia da valorização de uma reflexão interna, que (pensava) não carregar influências de suas experiências e sensibilidades - essa seria a chave para a produção de um conhecimento válido e verdadeiro, apto a ser universalizado (COSTA, 2018).

Essa tradição, característica do pensamento eurocentrado/ocidental, se apresentou durante muito tempo como a "única forma" de produção de conhecimento, que, ao se considerar universal, negou a capacidade/ possibilidade de outros para tal produção científica. Diversos autores ${ }^{1}$ sugerem que essa negação epistemológica, que também pode ser entendida como uma negação ao direito de alçar-se como sujeito produtor de conhecimento, se transforma, em última análise, em uma negação do direito à própria existência. O poema de Luiz Gama (1954, p. 130), escritor negro que viveu no Brasil Pós-Abolição, descreve tal situação:

Desculpa, meu amigo,

Eu nada te posso dar;

$\mathrm{Na}$ terra que rege o branco

Nos privam té de pensar! [...]

Ribeiro (2017), ao refletir sobre tal aspecto, cita ideias já desenvolvidas por Lélia Gonzáles, importante ativista e intelectual negra brasileira. De acordo com as autoras, o privilégio social é o que garante o privilégio epistêmico, uma vez que o modelo valorizado e universal de ciência é branco:

A consequência dessa hierarquização legitimou como superior a explicação epistemológica eurocêntrica conferindo ao pensamento moderno ocidental a exclusividade do que seria conhecimento válido, estruturando-o como dominante e assim inviabilizando outras experiências de conhecimento. (RIBEIRO, 2017, p. 24-25).

Desse modo, torna-se fundamental a reflexão de Maldonado-Torres (2007, p. 145), segundo a qual: "a desqualificação epistêmica se converte em instrumento privilegiado da negação ontológica". Com isso, entendese que o conhecimento científico, assim organizado e apresentado, configurou-se enquanto instrumento de dominação e hierarquização social. Isso

${ }^{1}$ Dentre os quais, podem-se destacar os mencionados ao longo deste texto. 


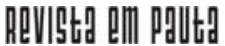

\} DECOLONIALIDADE E ESTUDOS CRÍTICOS - SILVA, C. F. S. \}

DOI: $10.12957 /$ REP.2020.51983

corrobora as ideias de Santos e Meneses (2009), quando introduzem a ideia de "pensamento abissal"2, segundo a qual esta negação produz, para além da negação de seu estatuto epistemológico, a consequente percepção de que os seres humanos estão no Norte e aqueles que estão no Sul são desprovidos de humanidade.

Assim configurou-se a lógica do "universalismo abstrato", que é fortemente criticada pela perspectiva decolonial. Costa (2018) e outros autores apontam que esse "universalismo abstrato" se caracterizou como a principal sustentação do projeto moderno/colonial, que está por trás da ideia de colonialidade do poder.

A colonialidade do poder, segundo Costa (2018, p. 121): "[...] refere-se à constituição de um padrão de poder em que a ideia de raça e o racismo se constituíram como princípios organizadores da acumulação do capital em escala mundial e das relações de poder no sistema mundo [...] moderno/ocidental". Assim, entende-se que, na nova lógica mundial que se iniciou com a modernidade - cuja formação começou com a escravização da população africana, dentre outros processos de violência mundo afora -, a diferença entre conquistadores e conquistados foi codificada a partir da ideia de raça (QUIJANO, 2005). De acordo com Almeida (2017, p. 40):

[...] processos de violência foram utilizados no capitalismo contra a população negra e povos indígenas em várias partes do planeta: a escravidão acompanhada do desterro; a imposição do uso da língua do colonizador; a demonização e destruição material e simbólica dos complexos e diversificados sistemas de crença seguido a cristianização; a separação familiar; o estupro e outras formas de violência sexual perpetrada contra as mulheres negras são algumas expressões do processo de objetificação do corpo negro.

A objetificação do corpo negro mencionada pela autora relacionase com a ideia de colonialidade do poder ${ }^{3}$, discutida acima. Dessa maneira, cabe entender que o processo de hierarquização dos diferentes grupos sociais ao redor do mundo a partir da ideia de raça sempre esteve a serviço de uma certa ordem, de uma tal perspectiva. Tais reflexões fazem com que, atualmente, essa "neutralidade científica" venha sendo questionada, fazendo com que o paradigma dominante perca sua "confiança epistemológica" (ESCOBAR, 2003, p. 639), ocasionando uma crise paradigmática.

Essa crise paradigmática está sendo utilizada para articulação de um "novo" modelo para produção de conhecimentos, construído na ação e elaborado por novos atores sociais, privilegiadamente vinculados aos

\footnotetext{
${ }^{2}$ A esse respeito, ver: Santos e Meneses (2009).

${ }^{3}$ A partir das ideias de Mignolo (2003), a colonialidade do poder se transforma, em última análise, em colonialidade do saber e colonialidade do ser. A esse respeito, ver: Mignolo (2003).
} 


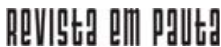

\} DECOLONIALIDADE E ESTUDOS CRÍTICOS - SILVA, C. F. S. \}

DOI: $10.12957 /$ REP.2020.51983

movimentos sociais. Esse "novo" conhecimento, portanto, se constrói a partir de uma identidade e de uma história.

Nesse sentido, o entendimento de Escobar (2003) vai ao encontro das ideias de Costa (2018), quando menciona a importância, para este "novo" conhecimento, do lugar de enunciação, ou lugar de fala ${ }^{4}$, bem como das influências do corpo, políticas e geopolíticas - é o "universalismo concreto", em oposição ao "universalismo abstrato" (COSTA, 2018).

Esse novo entendimento sobre o papel ocupado pela ciência na sociedade leva à compreensão de que o conhecimento deve voltar-se à mudança social. Para Escobar (2003, p. 640):

Se o paradigma científico dominante havia oposto as 'verdadeiras ciências' tanto ao senso comum como às humanidades, no novo modelo seria atribuído a estes últimos um lugar proeminente. Uma vez abandonados, necessariamente, os critérios convencionais de racionalidade e objetividade e reposto em cena o sujeito, teria então lugar uma revalorização das humanidades e um apelo à pluralidade metodológica e uma defesa do senso comum como crucial para todo o conhecimento. Duas outras questões se seguiram a re-subjetivação das ciências: o caráter necessariamente situado de todo o conhecimento e, concomitantemente, o fato de o conhecimento ser libertado, por assim dizer, do colete de forças da objetividade e da racionalidade e lhe permitir abordar a questão crucial de como viver vidas éticas num mundo crescentemente complexo e ambíguo.

Neste contexto se apresenta a perspectiva da decolonialidade, que se constitui como um projeto político-epistêmico, em que prevalece a importância da afirmação da corpo-geopolítica do conhecimento como forma de resistência à colonialidade do poder (COSTA, 2018). Analisando tal situação sob a perspectiva da população negra no Brasil, percebe-se que esse clamor por uma ideia de cientificidade ampliada se configura também como uma busca por um lugar de afirmação da humanidade como forma de resistência, mas também enquanto tentativa de ressignificação histórica, articulada pela população negra a partir de diferentes iniciativas.

A ideia é considerar que, para a produção do conhecimento, a experiência social de grupos dominados ou subalternos é importante, visto que foi abertamente desconsiderada e silenciada durante o período que organizou e concretizou o modelo vigente de "cientificidade". De acordo com Ribeiro (2017, p. 67): "[...] opressões estruturais impedem que indivíduos de certos grupos tenham direito à fala, à humanidade".

Aqui se localiza a discussão atual em torno do lugar de fala e sua relevância ou legitimidade no processo científico. Ribeiro (2017) desenvolveu diversas reflexões a esse respeito no livro intitulado $O$ que é lugar de fala?. A partir das contribuições da autora, pode-se entender que pensar

${ }^{4}$ Sobre esse assunto, ver: Ribeiro (2017). 


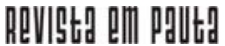

\} DECOLONIALIDADE E ESTUDOS CRÍTICOS - SILVA, C. F. S. \}

DOI: $10.12957 /$ REP.2020.51983

sobre lugar de fala envolve pensar as condições sociais do grupo de que se faz parte, da mesma forma que envolve pensar na maneira com que as experiências derivadas da participação neste grupo são partilhadas por essa pessoa com o grupo social. A autora sinaliza também que não se pode reduzir o ponto de vista às experiências individuais; o mais interessante seria refletir sobre o lugar social, visto que pertencer ao grupo negro na sociedade brasileira coloca o sujeito em um certo lugar social, diferenciado e não partilhado pelos que não possuem essa particularidade.

Quando incorporamos a essa discussão a perspectiva da afrosemeadura, vemos que esse lugar social pode ser compartilhado por pessoas de descendência africana em diversas partes do mundo, e não somente no Brasil. O termo afro-semeadura faz referência à citação de Luiz Silva Cuti (2012, n. p.), segundo a qual a expressão refere-se aos: "[...] termos apresentados pelo escritor colombiano Manuel Zapata, no $1^{\circ}$. Congresso de Culturas Negras das Américas, realizado em São Paulo, no ano de 1985. Zapata argumentava que seria uma expressão mais adequada, para o caso dos africanos arrancados do Continente, do que diáspora".

A reflexão a respeito da afro-semeadura, entendendo semear no sentido de lançar sementes à terra, nos permite vislumbrar a África como um grande berço a partir do qual espalharam-se as sementes, ou pessoas, que deram e darão diferentes frutos - esses frutos podem ser assemelhados às diversas formas de reexistência e reinvenção social da população negra ao redor do mundo.

No Brasil, tal perspectiva se configura para a população negra como possibilidade de reinventar-se histórica e socialmente, a partir da ressignificação de elementos relacionados à cultura africana, tendo a ver também com a ideia de renascimento. Essa ideia surge a partir do reconhecimento de que os elementos particulares da cultura africana - antes usados para hierarquizar e subestimar - agora podem ser utilizados como fonte de uma nova forma negra de ser e existir no mundo.

No próximo item, dar-se-á seguimento à discussão proposta, apresentando uma breve introdução aos estudos críticos do discurso, situando a relevância de sua utilização para a compreensão, abordagem e análise do racismo no Brasil.

\section{Os estudos críticos do discurso e as abordagens antirracistas no Brasil}

A discussão acima evidencia a relação estreita existente entre a dominação econômica, política e cultural e a dominação epistemológica, levando à hierarquização dos saberes e à negação das diversidades no campo científico em geral. Neste sentido, também se desenvolve a reflexão de Santos e Meneses (2009), que a partir da metáfora do "pensamento abissal" 


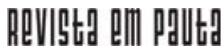

\} DECOLONIALIDADE E ESTUDOS CRÍTICOS - SILVA, C. F. S. \}

DOI: $10.12957 /$ REP.2020.51983

defendem que o pensamento moderno se organiza em um sistema de diferenciações visíveis e invisíveis, que separam a realidade social em dois universos ontologicamente diferentes: de um lado está o Norte imperial, colonial e neocolonial, e de outro lado está o Sul colonizado, silenciado e oprimido.

A partir desta compreensão, percebe-se que o Sul tem uma realidade totalmente forjada pelos interesses do Norte (TAVARES, 2009). Para Santos e Meneses (2009, p. 24): "o que caracteriza este pensamento abissal é a impossibilidade de co-presença entre os dois lados da linha referidos". Isso faz com que quaisquer pretensões de ascensão do Sul ou de suas ideias precise passar necessariamente por um reposicionamento que questione as diferentes formas de dominação, sejam econômica, política e cultural ou epistemológica. Esse ponto será retomado mais tarde no texto.

Os aspectos que se referem à dependência do Sul com relação ao Norte, mencionados pelos autores acima, apontam no mesmo sentido das ideias propostas pela teoria marxista da dependência, desenvolvida a partir dos anos 1960 por diversos autores ${ }^{5}$. Essa teoria busca compreender a condição dependente dos países periféricos como parte da própria lógica de funcionamento do capitalismo na economia mundial (CARCANHOLO, 2013). No que pesem as diferentes concepções das linhas teóricas mencionadas acima, considera-se válida sua utilização em conjunto, visto que ambas, mesmo divergentes em alguns momentos, apresentam pontos de convergência para a compreensão da discussão ora proposta.

Marini (1973) afirma que o sistema capitalista só pode ser compreendido em sua totalidade e é regido por uma "dialética de dependência". Além disso, de acordo com Ortegal (2018, p. 426): "Nesta perspectiva, desenvolvimento e subdesenvolvimento ou dependência, estão profundamente conectados, de modo que a dependência e subordinação dos países de capitalismo periférico são o outro lado da moeda do desenvolvimento de países centrais".

Neste contexto é que se desenvolveram as relações raciais no Brasil, marcadas pela dependência e subordinação, bem como pela herança colonial e escravista. Essa foi reatualizada e reaproveitada para a nova realidade social do país, ao invés de ser superada (ORTELGAL, 2018), mesmo após a Proclamação da Independência, em 1822, e da República, em 1889. $\mathrm{Na}$ análise de Nogueira (2006) e de outros autores, a sociedade brasileira teve seu desenvolvimento fortemente travado pela escravização da população negra, visto que ela ocupava o centro do organismo social brasileiro, formando um verdadeiro sistema caracterizado por dois mundos que mal se comunicavam. De acordo com o autor, em meados do século XIX, no Brasil:

[...] tínhamos uma sociedade tradicional em pleno vigor, apenas levemente tocada pela modernização capitalista. A sociedade era mo-

${ }^{5}$ Dentre eles, pode-se mencionar: Carcanholo (2013), Marini (1990) e Fernandes (1973). 


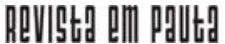

\} DECOLONIALIDADE E ESTUDOS CRÍTICOS - SILVA, C. F. S. \}

DOI: $10.12957 /$ REP.2020.51983

delada pela escravidão e dividia-se basicamente em duas partes, uma oprimindo, explorando e humilhando a outra. O Estado, agigantado artificialmente, não funcionava como um ator que se debruçasse de modo ativo sobre a sociedade, que planejasse seu desenvolvimento, a amparasse e promovesse. Não existiam, a rigor, políticas públicas. A democracia engatinhava e era tão imperfeita e tão vazia de povo que seria mesmo o caso de perguntar se existia ou cumpria alguma função. (NOGUEIRA, 2006, p. 174).

Neste cenário, o racismo foi fortemente enraizado no modo de ser brasileiro, e o convívio com outros "vícios" demarcou a fragilidade da própria ideia de democracia e república. Para Nogueira (2006, p. 175):

[...] a República foi organizada a partir de um jogo político regionalista, oligárquico e excludente que reproduziu o fosso entre povo e Estado, deformou a representação e descaracterizou a própria ideia federativa, que havia sido anunciada como um de seus grandes trunfos. Apenas nominalmente seria um sistema democrático: na verdade, fincou raízes em um localismo mandonista e em práticas clientelísticas autoritárias, desinteressadas da cidadania.

Neste contexto, como será possível pensar formas de pautar o racismo na sociedade brasileira? Como fazer emergir a discussão sobre o racismo nesse cenário que preza pelo seu silenciamento?

O silenciamento sobre as relações raciais no Brasil pode ser entendido como um subproduto da ideologia do branqueamento desenvolvida pelas elites brasileiras, em meados do século XIX e início do XX. Essa ideologia foi evidenciada nas ciências, nas artes, nas pesquisas e na imprensa, demonstrando a expectativa dessas elites de que o Brasil se tornasse um país branco. Tal ideologia materializou-se na política de branqueamento desenvolvida pelo Estado brasileiro, que promoveu a entrada maciça de imigrantes europeus no país no período imediatamente anterior ao advento do trabalho livre e ao desenvolvimento do capitalismo experimentado no país. De acordo com Ortegal (2018, p. 418):

Nesse processo de transição do regime escravista para o capitalista, a mão de obra escravizada passa a ser substituída pela mão de obra livre e assalariada. Isso, porém, não significa dizer que o trabalhador que antes era escravizado foi absorvido como assalariado. Num sentido contrário [...], demonstram a intensificação da importação de mão de obra de países europeus, com vistas a substituir os trabaIhadores negros, movidos pela ideologia racista do sucessivo branqueamento da população brasileira. É nesse contexto, então, que se formam no Brasil as classes sociais capitalistas.

Com o passar do tempo, a ideologia do branqueamento sofreu alterações no imaginário social, especialmente quanto a suas funções e 


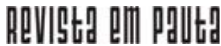

\} DECOLONIALIDADE E ESTUDOS CRÍTICOS - SILVA, C. F. S. \}

DOI: $10.12957 /$ REP.2020.51983

sentidos. No entanto, permanece presente no imaginário social brasileiro, causando impactos inclusive com relação à autopercepção da pessoa negra.

Em conjunto com isso, outro fator determinante para compreensão da forma como se caracteriza o contexto racial brasileiro é o papel desempenhado pelo mito da democracia racial. Diz-se que a democracia racial é um mito porque esse pensamento foi ancorado na ideia de que no Brasil não havia diferenças ou hostilidades entre os grupos das diferentes raças que aqui habitavam. Esse mito foi também desenvolvido pelas elites intelectuais e amplamente difundido, tanto no contexto nacional quanto internacional, sendo um dos principais expoentes desta perspectiva Gilberto Freire, que narrou de forma romântica no livro Casa grande e senzala o processo de violência e desumanização a que foi submetida a população negra escravizada.

Considerando os elementos destacados acima sobre a forma como o racismo se configura na sociedade brasileira, é fundamental analisar a importância do discurso como forma de explicitar o racismo nos diversos modos de interação social, demonstrando como ele se faz presente na estrutura social. Mas de que discurso estamos falando? Qual o significado aqui empregado para este termo?

Um dos autores referência no debate acerca do discurso e da reprodução discursiva do racismo é Van Dijk (2015), que desenvolve diversos estudos sobre o tema. Para o autor, o discurso é entendido como uma interação ou prática social, situado social, histórica, cultural e politicamente.

Partindo dessa compreensão, o autor propõe que, para analisar um determinado discurso, deve-se observá-lo não só sob a perspectiva linguística, denominada estrutura discursiva, mas também por meio das relações que essas estruturas discursivas estabelecem com as estruturas sociais, tais como corporações, posições de poder, movimentos sociais etc. Assim, entende-se que as estruturas sociais influenciam os usuários da língua na produção de discursos, materializando-as através das estruturas discursivas (VAN DIJK, 2015).

Os estudos deste autor inscrevem-se na linha dos estudos críticos do discurso (ECD) ou análise crítica do discurso (ACD). De acordo com ele:

A Análise Crítica do Discurso (ACD) é um tipo de investigação analítica discursiva que estuda principalmente o modo como o abuso de poder, a dominação e a desigualdade são representados, reproduzidos e combatidos por textos orais e escritos no contexto social e político [...] os analistas críticos do discurso adotam um posicionamento explícito e, assim, objetivam compreender, desvelar e, em última instância, opor-se à desigualdade social. (VAN DIJK, 2015, p. 113).

É importante compreender que a ACD: "[...] pode ser vista como uma reação contra os paradigmas formais dominantes (muitas vezes associais 


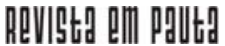

\} DECOLONIALIDADE E ESTUDOS CRÍTICOS - SILVA, C. F. S. \}

DOI: $10.12957 /$ REP.2020.51983

e acríticos) dos anos 1960 e 1970" (VAN DIJK, 2015, p. 114). Neste sentido, os ECD têm suas propostas interessadas de forma especial no estudo (crítico) de questões sociais, bem como da desigualdade social, da dominação e de fenômenos a elas relacionados. Fazem isso, porém, buscando desvendar o papel do discurso, do uso linguístico e da comunicação.

Para Van Dijk (2015, p. 15): "Esses pontos claramente implicam que estudiosos dos ECD não são 'neutros', mas se comprometem com um engajamento em favor dos grupos dominados na sociedade. Eles assumem uma posição e fazem isso de modo explícito". Nesta perspectiva, percebese que os analistas críticos do discurso reforçam a tradição que rejeita a possibilidade de uma ciência "não valorativa" ou "neutra", então para eles: "[...] é fundamental ter a consciência explícita do seu papel na sociedade" (VAN DIJK, 2015, p. 114).

Segundo esta compreensão, o discurso é utilizado enquanto ferramenta de dominação e reprodução do racismo: "[...] especialmente nas sociedades contemporâneas da informação, o discurso reside no coração do racismo" (VAN DIJK, 2015, p. 134). Considerando a centralidade que o racismo assume na discussão de Van Dijk (2015, p. 134), ele assim define essa categoria: "racismo é um complexo sistema social de dominação, fundamentado étnica ou 'racialmente', e sua consequente desigualdade".

O autor defende, ainda, que o racismo é um sistema formado por um subsistema social e um cognitivo (VAN DIJK, 2015, p. 134), sendo que: "o subsistema social é constituído por práticas sociais de dominação no (micro) nível local, e por relações de abuso de poder por grupos, organizações e instituições dominantes em um (macro) nível de análise". Já o segundo subsistema de racismo é cognitivo:

Mesmo que as práticas discriminatórias dos membros de grupos e instituições dominantes constituam as manifestações visíveis e tangíveis do racismo cotidiano, essas práticas também possuem uma base mental que consiste em modelos tendenciosos de interações e eventos étnicos, que por sua vez encontram-se enraizados em preconceitos e ideologias racistas. (VAN DIJK, 2015, p. 134-135).

A partir dessas contribuições, percebe-se que as possibilidades de reprodução do racismo no ambiente social se relacionam diretamente com a formação e disseminação de ideologias racistas. Tais ideologias, como também os preconceitos raciais, podem ser vislumbrados como responsáveis pela reprodução discursiva do racismo, especialmente através da comunicação:

O discurso também desempenha um papel fundamental para essa dimensão cognitiva do racismo. As ideologias e os preconceitos étnicos não são inatos e não se desenvolvem espontaneamente na interação étnica. Eles são adquiridos e apreendidos, e isso normalmente ocorre através da comunicação, ou seja, através da escrita e da fala. 
E vice-versa: essas representações mentais do racismo são tipicamente expressas, formuladas, defendidas e legitimadas no discurso e podem assim ser reproduzidas e compartilhadas dentro do grupo dominante. Esse é essencialmente o modo como o racimo é 'aprendido' na sociedade. (VAN DIJK, 2015, p. 135).

Assim, vemos que esse modo de "aprender" o racismo deriva de uma certa forma de "ensinar" o racismo, que está disseminada nos diferentes contextos sociais do Ocidente, desde a convivência cotidiana e corriqueira da população em geral, até os meios científicos mais qualificados. Isso faz com que todos devam ocupar-se de tentar decifrar qual o papel e a relação da ciência e, em particular, do discurso acadêmico, diante da forma como se configura a estrutura social racista.

Sabe-se que o discurso científico e acadêmico é influenciado por essa estrutura racista, além de ser produzido na interação social. Nesse sentido, cabe a reflexão "[...] de como a linguagem dominante pode ser utilizada como forma de manutenção de poder, uma vez que exclui indivíduos que foram apartados das oportunidades de um sistema educacional justo" (RIBEIRO, 2017, p. 26).

\section{Considerações finais}

A partir das reflexões sinalizadas ao longo do texto, percebe-se que a perspectiva da decolonialidade, em conjunto com os ECD, pode se constituir enquanto importante ferramenta de compreensão e análise das relações raciais no Brasil. Isso, considerando que ambas as abordagens tecem críticas ao processo epistemológico que tem pretensões universalizantes, reduzindo o conhecimento a um único paradigma e descontextualizando social e politicamente o conhecimento produzido.

Assim, tendo em vista o propósito de contribuir para uma mudança social específica em favor dos grupos dominados ou subalternos, neste caso, a população negra no Brasil, os conceitos discutidos no texto podem contribuir para uma abordagem antirracista. Cabe mencionar que diante da constatação de que o racismo faz parte das relações de dominação e exploração na sociedade capitalista, o antirracismo se apresenta como um conjunto de posturas ou comportamentos, éticos e também políticos, a serem desempenhados pelas pessoas na convivência em sociedade.

Dessa forma, entende-se que tal perspectiva de análise da questão estudada vem a contribuir para o (necessário) reposicionamento da população negra no Brasil, com vistas à afirmação e ascensão de ideias e concepções (negras) para enfrentar as diferentes formas de dominação conformadas pelo racismo. 


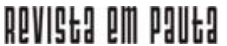

\} DECOLONIALIDADE E ESTUDOS CRÍTICOS - SILVA, C. F.S. \}

DOI: $10.12957 /$ REP.2020.51983

\section{Referências}

ALMEIDA, M. S. Diversidade humana e racismo: notas para um debate radical no serviço social. Revista Argum, v. 9, n. 1, jan./abr. 2017.

CARCANHOLO, M. D. O atual resgate crítico da teoria marxista da dependência. Trabalho, Educação e Saúde, Rio de Janeiro, v. 11, n. 1, 2013.

COSTA, J. B. Decolonialidade, atlântico negro e intelectuais negros brasileiros: em busca de um diálogo horizontal. Revista Sociedade e Estado, vol. 33, n. 1, jan./abr. 2018.

CUTI, L. S. O leitor e o texto afro-brasileiro. Nov. 2012. Disponível em: https://vinteculturaesociedade.wordpress.com/2012/11/22/o-leitor-e-otexto-afro-brasileiro/. Acesso em: 23 jun. 2019.

ESCOBAR, A. Atores, redes e novos produtores de conhecimento: os movimentos sociais e a transição paradigmática nas ciências. In: SANTOS, B. (org.). Conhecimento prudente para uma vida descente: um discurso sobre a ciência revisitado. São Paulo: Cortez, 2003.

FERNANDES, F. Capitalismo dependente e classes sociais na América Latina. Rio de Janeiro: Zahar, 1973.

GAMA, L. G. P. Luiz Gama e suas trovas burlescas. Rio de Janeiro: Casa do Estudante do Brasil: 1954.

MALDONADO-TORRES, N. Descolonización y el giro des-colonial. Tabula Rasa, n. 9, 2008.

MARINI, R. M. A dialética da dependência. Local: Rio de Janeiro. Editora Era, 1990.

MIGNOLO, W. Histórias locais/projetos globais: colonialidade, saberes subalternos e pensamento limiar. Belo Horizonte: Editora UFMG, 2003.

NOGUEIRA, M. A. Público e privado na formação social brasileira: velhas, novas e novíssimas tensões. Trabalho, educação e saúde, v. 4, n. 1, 2006.

ORTEGAL, L. Relações raciais no Brasil: colonialidade, dependência e diáspora. Serviço social e Sociedade, n. 133, set./dez. 2018.

QUIJANO, A. Colonialidade do poder, eurocentrismo e América Latina. In: LANDER, E. (org.). A colonialidade do saber: eurocentrismo e ciências sociais. Perspectivas latino-americanas. Buenos Aires: Clacso - Consejo Latinoameriano de Ciencias Sociales, 2005.

RIBEIRO, D. O que é lugar de fala? Belo Horizonte: Letramento, 2017.

SANTOS, B. S.; MENESES, M. P. (org.). Epistemologias do sul. Coimbra: Almeidina, 2009.

TAVARES, M. Recensão. Revista Lusófona de Educação, 2009. 


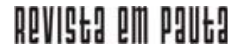

\} DECOLONIALIDADE E ESTUDOS CRÍTICOS -SILVA, C. F. S.

DOI: $10.12957 /$ REP.2020.51983

VAN DIJK, T. A. Discurso de poder. São Paulo: Contexto, 2015.

DOI: $10.12957 /$ rep.2020.51983

Recebido em 21 de julho de 2019.

Aprovado para publicação em 16 de março de 2020.

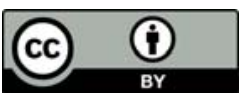

A Revista Em Pauta: Teoria Social e Realidade Contemporânea está licenciada com uma Licença Creative Commons Atribuição 4.0 Internacional. 